\title{
Differential Effects of Unipolar versus Bipolar Depression on Episodic Memory Updating
}

\author{
Bhaktee Dongaonkar $\mathrm{PhD}^{1}$, Almut Hupbach $\mathrm{PhD}^{2}$, Lynn Nadel $\mathrm{PhD}^{3}$, Sumantra Chattarji $\mathrm{PhD}^{1,4,5}$ \\ ${ }^{1}$ National Center for Biological Sciences, Tata Institute of Fundamental Research, Bangalore 560065, \\ India \\ ${ }^{2}$ Department of Psychology, Lehigh University, Bethlehem, Pennsylvania, USA \\ ${ }^{3}$ Department of Psychology, University of Arizona, Tucson, Arizona, USA \\ ${ }^{4}$ Centre for Brain Development and Repair, Institute for Stem Cell Biology and Regenerative Medicine, \\ Bangalore 560065, India \\ ${ }^{5}$ Centre for Discovery Brain Sciences, Deanery of Biomedical Sciences, University of Edinburgh, Hugh \\ Robson Building, 15 George Square, Edinburgh EH89XD, UK
}

Running title: Memory Updating in Depression

Word count of the abstract -267

Number of figures -03 (colored)

Number of tables - 01

Number of supplement -0 


\begin{abstract}
Episodic memories, when reactivated, can be modified or updated by new learning. Since such dynamic memory processes remain largely unexplored in psychiatric disorders, we examined the impact of depression on episodic memory updating. Unipolar and bipolar depression patients, and age/education matched controls, first learned a set of objects (List-1). Two days later, participants in all three groups were either reminded of the first learning session or not followed by the learning of a new set of objects (List-2). Forty-eight hours later, List-1 recall was impaired in unipolar and bipolar patients compared to control participants. Further, as expected, control participants who received a reminder spontaneously recalled items from List-2 during recall of List-1, indicative of an updated List-1 memory. Such spontaneous intrusions were also seen in the unipolar and bipolar patients that received the reminder, suggesting that memory updating was unaffected in these two patient groups despite impaired recall of List 1. Unexpectedly, we observed a trend towards higher intrusions, albeit statistically insignificant, not only in the reminder but also in the no-reminder subgroups of bipolar patients. We probed this further in a second cohort by testing recall of List-2, which was also impaired in both depression groups. Again bipolar patients showed intrusions, but this time in the reverse order from List-1 into List-2, independent of a reminder. Taken together, despite impaired recall, updating of episodic memories was intact and unidirectional in unipolar depression. In contrast, indiscriminate updating, as evidenced by bidirectional interference between episodic memories, was seen in bipolar depression. These findings reveal a novel distinction between unipolar versus bipolar depression using a reactivation-dependent memory updating paradigm.
\end{abstract}

Keywords: list learning, delayed recall, episodic memory updating, unipolar depression, bipolar depression, memory reactivation. 


\section{Introduction}

The debilitating psychiatric symptoms of depression comprise a range of cognitive deficits that include episodic memory impairment. Previous clinical studies on episodic memory in both unipolar and bipolar depression have reported deficits in free recall and recognition (Airaksinen et al. 2004; Austin et al. 1992; Bearden et al. 2006a,b; Fossati et al. 2004; Kizilbash et al. 2002; Pauls et al. 2015; Sweeney et al. 2000; Van Gorp et al. 1999). Neuroimaging and post-mortem studies involving patients of both types of depression have also identified loss of volume in the hippocampus (Blumberg et al. 2003; Bremner et al. 2004; Haukvik et al. 2015; Huang et al. 2013; Konradi et al. 2011; Sheline et al. 1996; Treadway et al., 2015), which is necessary to encode and retrieve episodic memories (Eldridge et al. 2000; Nadel et al. 2000).

Episodic memory is a dynamic and complex process that involves more than just retention and recall. Consolidation of new memory representations extends beyond the period of learning. This involves offline processing, which continues into sleep overnight that stabilizes and integrates newly learned information into existing memory networks for long-term access (Born and Wilhelm 2012; Marshall and Born 2007; Stickgold and Walker 2007). Moreover, memories can be modified when reactivated. Upon reactivation, memories become labile and can be weakened (Nader et al. 2000; Schiller et al. 2010), strengthened (Lee 2008), or updated with relevant information (Das et al. 2015; Haubrich et al. 2015; Hupbach et al. 2007, 2008; Olshavsky et al. 2013). Such dynamic processes depend on interactions between a number of brain regions, including the hippocampus and prefrontal regions (Bledowski et al. 2009; Blumenfeld and Ranganath 2007; Cabeza and Nyberg 2000; Cohen et al. 1997; Nyberg et al. 1996, 2000; Schlichting and Preston 2016). Much like the hippocampus, subgenual and medial prefrontal regions also undergo structural, functional, and volumetric changes in unipolar and bipolar depression (Cotter et al. 2002; Drevets et al. 1997, 1998; Rajkowska et al. 1999; Rajkowska 2000; Salvadore et al. 2011; Treadway et al. 2015). 
Despite this growing body of evidence, study of how depression affects episodic memory has been largely restricted to assessments of learning followed by memory testing within the same session, with intervals ranging from a few seconds to at most an hour (Airaksinen et al. 2004; Bearden et al. 2006a,b; Fossati et al. 2004). These studies did not examine the effects of depression on memory consolidation or delayed recall over days. The sole exception is Nissen and colleagues (2010), who observed that unipolar depression impaired retention of well-learned word pairs a day later, suggesting impaired consolidation in depression. Delayed recall, over days, has not been studied in bipolar depression to date. These gaps in knowledge raise several questions. If hippocampal and prefrontal function is compromised in both types of depression, then is delayed recall, over days, also impaired in both? Assuming that updating a consolidated episodic memory requires hippocampal and prefrontal interaction, will depression affect the ability to update a previously acquired episodic memory? Importantly, is updating affected to the same extent in unipolar and bipolar depression? The present study explores these questions using an established episodic memory updating paradigm over multiple sessions spanning 5 days (Hupbach et al., 2007).

\section{Materials and Methods}

\subsection{Participants}

This study was approved by Institutional Ethics Committees at the National Institute of Mental Health and Neurosciences (NIMHANS) and at the National Center for Biological Sciences. Participants between 18-58 years of age provided written consent.

Forty-seven unipolar depression and 48 bipolar depression in-patients from the psychiatry wards at NIMHANS completed the study. Patients were diagnosed by MD psychiatrists at NIMHANS and those meeting unipolar or bipolar depression criteria according to DSM-5 were included. Forty-six age and education matched control participants were recruited from the community through advertisements. 
Patients and controls were excluded if they had (a) history of brain injury, (b) neurological disorder, epileptic attacks, or loss of consciousness, (c) dementia, (d) mental retardation, or (e) electroconvulsive therapy (ECT) within the past 6 months. Clinical symptoms of depression and mania were rated using the 17-item Hamilton Depression Rating Scale (HDRS, Hamilton, 1960) and the 11-item Young Mania Rating Scale (YMRS, Young et al., 1978), respectively, on the day of Session 1. Patients with comorbid anxiety, obsessive-compulsive disorder, or substance use were included if these disorders were not the primary reason for hospitalization. All patients had been taking their ongoing medication for at least 2 weeks and they continued doing so while participating in this study. Details of demographic details, clinical symptoms, and medication of patients are summarized in Table 1.

Table 1. Participant characteristics and medication

\begin{tabular}{|c|c|c|c|c|c|c|c|c|}
\hline \multirow[b]{2}{*}{ Characteristic } & \multicolumn{4}{|c|}{ Experiment 1} & \multicolumn{4}{|c|}{ Experiment 2} \\
\hline & Control & $\begin{array}{c}\text { Unipolar } \\
\text { Depression }\end{array}$ & $\begin{array}{c}\text { Bipolar } \\
\text { Depression } \\
\end{array}$ & Statistic & Control & $\begin{array}{c}\text { Unipolar } \\
\text { Depression } \\
\end{array}$ & $\begin{array}{c}\text { Bipolar } \\
\text { Depression } \\
\end{array}$ & Statistic \\
\hline $\mathrm{N}$ & 46 & 47 & 48 & - & 32 & 33 & 29 & - \\
\hline Males/Females & $32 / 14$ & $26 / 21$ & $33 / 15$ & $\begin{array}{c}\chi^{2}=2.61 \\
p=0.3\end{array}$ & $20 / 12$ & $13 / 20$ & $17 / 12$ & $\begin{array}{c}\chi^{2}=3.94 \\
\mathrm{p}=0.14\end{array}$ \\
\hline $\begin{array}{r}\text { Age } \\
\text { (years) }\end{array}$ & $30(7.6)$ & $33.6(12.3)$ & $30.9(9.2)$ & $\begin{array}{c}F=1.65 \\
p=0.2\end{array}$ & $28.7(7.2)$ & $30.9(10.1)$ & 31.7 (11.6) & $\begin{array}{l}F=0.77 \\
p=0.46\end{array}$ \\
\hline $\begin{array}{r}\text { Education } \\
\text { (years) }\end{array}$ & $14.9(4.9)$ & $13.3(3.1)$ & $14.5(3)$ & $\begin{array}{l}F=2.6 \\
p=0.08\end{array}$ & $13.8(4.8)$ & $13.8(2.6)$ & $14(2.9)$ & $\begin{array}{c}\mathrm{F}=0.04 \\
\mathrm{p}=0.9\end{array}$ \\
\hline $\begin{array}{r}\text { Depressive } \\
\text { symptoms } \\
\text { (HDRS) } \\
\end{array}$ & $1.2(1.6)$ & $18.8(6.3)$ & $13.4(3.8)$ & $\begin{array}{l}\mathrm{F}=25.9 \\
\mathrm{p}<0.001 \\
(\mathrm{U} \text { vs B })\end{array}$ & $1.0(1.5)$ & $17(4.5)$ & $14.5(4.3)$ & $\begin{array}{c}F=5.1 \\
p=0.028 \\
(U \text { vs B })\end{array}$ \\
\hline $\begin{array}{r}\text { Mania symptoms } \\
(\text { YMRS) }\end{array}$ & - & $5.8(2.1)$ & $13.8(4.8)$ & $\begin{array}{c}\mathrm{F}=108.02 \\
\mathrm{p}<0.001\end{array}$ & - & $4.8(2.8)$ & $11.1(5.1)$ & $\begin{array}{l}F=36.6 \\
p<0.001\end{array}$ \\
\hline $\begin{array}{cr}\text { Moderate } & \text { YMRS } \\
\text { depression } & \leq 12\end{array}$ & - & 18 & 12 & - & - & 17 & 9 & - \\
\hline $\begin{array}{cc}\text { HDRS } & \text { YMRS } \\
(11-16) & (13-19) \\
\end{array}$ & - & 0 & 24 & - & - & 0 & 9 & - \\
\hline $\begin{array}{r}\text { Severe depression } \\
\text { HDRS } \geq 17 \& \\
\text { YMRS } \leq 12\end{array}$ & - & 29 & 9 & - & - & 16 & 9 & - \\
\hline $\begin{array}{r}\text { Mixed state } \\
\text { HDRS } \geq 17 \& \\
\text { YMRS } \geq 12\end{array}$ & - & 0 & 3 & - & - & 0 & 2 & - \\
\hline $\begin{array}{l}\text { Comorbid anxiety, } \\
\text { OCD, substance use }\end{array}$ & - & 13 & 7 & $\begin{array}{l}\chi 2=1.9 \\
p=0.12\end{array}$ & - & 15 & 9 & $\begin{array}{c}\chi^{2}=1.34 \\
p=0.25\end{array}$ \\
\hline $\begin{array}{r}\text { General Health } \\
\text { (GHQ) } \\
\end{array}$ & $12.5(4.4)$ & - & - & - & $14.9(5.9)$ & - & - & - \\
\hline Trait Anxiety (STAI) & $29.4(6.3)$ & - & - & - & $33.0(8.3)$ & - & - & - \\
\hline $\begin{array}{r}\text { Age at onset } \\
\text { (years) }\end{array}$ & - & $26.6(11.9)$ & $21.9(7.9)$ & $\begin{array}{l}\mathrm{F}=4.99 \\
\mathrm{p}=0.03\end{array}$ & - & $22.4(8.5)$ & $23.8(10.8)$ & $\begin{array}{c}\mathrm{F}=0.28 \\
\mathrm{p}=0.6\end{array}$ \\
\hline
\end{tabular}




\begin{tabular}{|c|c|c|c|c|c|c|c|c|}
\hline $\begin{array}{r}\text { Illness Duration } \\
\text { (years) }\end{array}$ & - & $7.04(6.8)$ & $9.4(6.1)$ & $\begin{array}{l}F=3.17 \\
p=0.08\end{array}$ & - & $8.4(7.2)$ & $7.9(6.5)$ & $\begin{array}{l}F=0.07 \\
p=0.78\end{array}$ \\
\hline \multicolumn{9}{|c|}{ Current Medication (N) } \\
\hline Drug naïve & - & 0 & 0 & - & & 0 & 0 & - \\
\hline Mood stabilizer & - & 11 & 43 & $\begin{array}{c}\chi^{2}=41.18 \\
p<0.001\end{array}$ & - & 9 & 25 & $\begin{array}{l}\chi^{2}=21.3 \\
\mathrm{p}<0.001\end{array}$ \\
\hline Anti-Psychotic & - & 16 & 39 & $\begin{array}{c}\chi^{2}=20.43 \\
\mathrm{p}<0.001\end{array}$ & - & 15 & 24 & $\begin{array}{l}\chi^{2}=9.06 \\
p=0.003\end{array}$ \\
\hline Anti-Depressant & - & 39 & 12 & $\begin{array}{c}\chi^{2}=36.33 \\
p<0.001\end{array}$ & - & 30 & 8 & $\begin{array}{l}\chi^{2}=25.67 \\
p<0.001\end{array}$ \\
\hline Anti-Anxiety & - & 38 & 33 & $\begin{array}{c}\chi_{2}=3.42 \\
\mathrm{p}=0.06\end{array}$ & - & 30 & 22 & $\begin{array}{l}\chi 2=2.5 \\
p=0.11\end{array}$ \\
\hline
\end{tabular}

Values in parentheses (SD). $\mathrm{N}=$ number of participants; $\mathrm{U}=$ Unipolar depression; B=Bipolar depression; HDRS=Hamilton

Depression Rating Scale; YMRS=Young Mania Rating Scale; OCD=Obsessive Compulsive Disorder; GHQ=General Health Questionnaire; STAI=Spielberger Trait Anxiety Inventory.

Control participants were screened using the non-patient version of the Structured Clinical Interview. Additional screening measures for control participants included the 28 -item General Health Questionnaire (GHQ, Goldberg and Hiller, 1979) and the 20-item Spielberger's Trait Anxiety Inventory (STAI, Spielberger et al., 1983) to assess mental health and trait anxiety levels respectively. Control participants scoring GHQ<25 (Sterling, 2011) and STAI $\leq 47$ (mild-moderate trait anxiety (Bödecs et al., 2013; Hermanns et al., 2005) were included (Table 1).

Three unipolar depression patients underwent a change in treatment plan - ECT was scheduled on the day of Session 3. Two bipolar depression patients were unwilling to complete Session 3 and their Session 3 recall test was incomplete. These patients were excluded from the analysis. Four control participants had rehearsed or written down items from List 1 or List 2, in the intervening period until Session 3, and were therefore excluded from the analysis.

\subsection{Material}

Study material consisted of two lists of everyday objects similar to those used by Hupbach et al. (2007).

List 1 had 20 objects (balloon, calculator, toy-car, toy cherry, dice, feather, flower, fork, glue, key, pencil, 
ribbon, sock, sponge, teabag, toothbrush, tennis-ball, thread, torch, and whistle). List 2 had 20 different everyday objects (band-aid, battery, book, cassette tape, cellphone, chain, coin, comb, cup, envelope, kerchief, paper-clip, toy pan, pebble, screwdriver, soap, straw, sunglasses, toy tiger, and watch).

\subsection{Episodic Memory Updating Protocol}

All sessions were conducted between 10am and 5pm. The procedure is outlined in Figure 1A.

Session 1- Learning of List 1: All participants were shown 20 everyday objects (List 1). The experimenter removed one object at a time from a bag and placed it on a table in front of the participant for a few seconds. The participant was instructed to name and observe every object carefully. The experimenter then put the object away in a basket. After showing all 20 objects one by one, the material was taken out of sight. The experimenter engaged the participant in a 30s conversation to prevent rehearsal. Subsequently, the participant was asked to recall as many objects as possible and the experimenter recorded the recalled objects. The presentation of objects was repeated until the participant recalled 17 of the 20 items or up to a maximum of 4 learning trials. At this point Session 1 ended and before leaving the participants were instructed not to think or write about the study, nor to discuss it with anyone.

Session 2- Reminder Manipulation and Learning of List 2: Two days (48hrs) later, participants were randomly assigned by the experimenter to a reminder or no-reminder group. Participants in the reminder group went to the same room in which Session 1 had taken place and were asked a reminder question to elicit reactivation - "Do you remember what you did on the first day? Can you describe what you did?" Participants in the no-reminder group went to a different room and were not asked any question. Both groups were then shown another set of 20 everyday objects (List 2) which were kept in a box, different from that used in Session 1. This time all 20 objects were put on the table at once and were quickly spread out in front of the participant. This different method of presentation was used to reduce the commonality between the learning procedures in Sessions 1 and 2 and thereby prevent automatic reactivation of List 1 
memory in the no-reminder groups. Participants were asked to name each object and were given an additional 30s to study all of them. The objects were then taken out of sight and participants were engaged in a 30s conversation. Similar to List 1 learning, List 2 objects were shown until 17 of 20 were learned or up to 4 learning trials. Once again they were told to not think, write or discuss about the study at the end of Session 2.

Session 3- List Recall: Two days (48hrs) after Session 2, all participants went back to the Session 1 testing room. In Experiment 1, participants were instructed to recall as many objects as possible from Session 1 (List 1) over 4 recall trials (Figure 1A). In Experiment 2, participants were instructed to recall as many objects as possible from Session 2 (List 2) over 4 recall trials (Figure 2A). A 1-2 min conversation intervened every recall attempt.

At the end of Session 3, before debriefing, the experimenter enquired if participants had thought about List 1 or List 2, spoken to anyone regarding it, or had written down items from either list during the intervening period until Session 3. Those participants who had rehearsed, written down, or spoken about either list were excluded from the analysis.

\section{Results}

\subsection{Experiment 1}

As described in the methods above, in Experiment 1, all participants learned List 1 on Day 1 (Session 1) (Figure 1A). Later, on Day 3 (Session 2), participants from each diagnostic group were randomly divided into two groups, one of which was given a reminder while the other was not. Subsequently, the reminder and no-reminder groups learned a new list of 20 objects (List 2) on Day 3. Finally, on Day 5 (Session 3), all groups were tested for recall of List 1. The unipolar, bipolar, and control groups are collectively referred to as 'diagnostic group' for statistical analysis. 


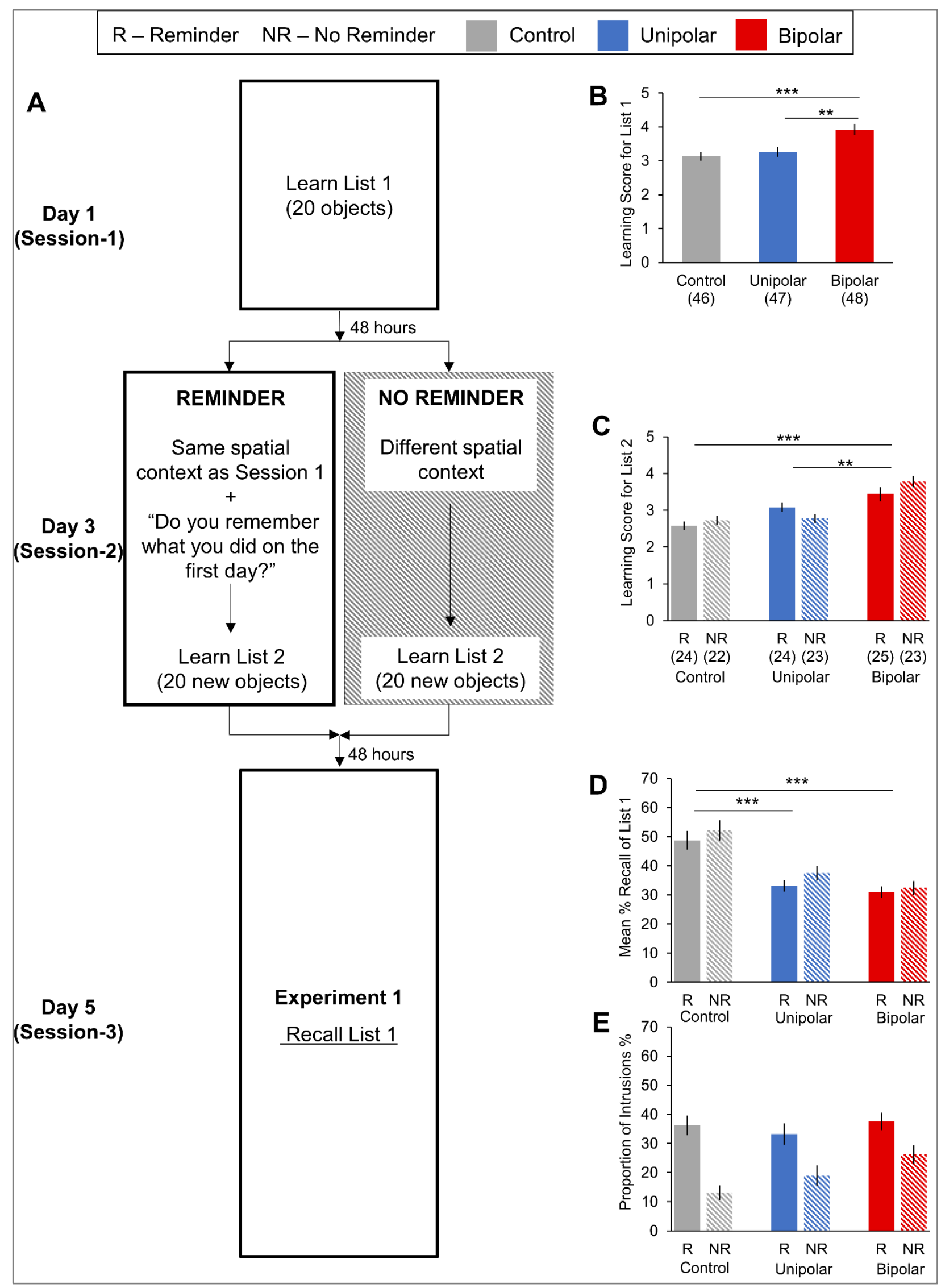


Figure 1. Effects of unipolar and bipolar depression on list learning and recall of List 1 (Experiment 1). (A) Experimental design spanning three sessions. (B) List 1 learning performance in Session 1 (Day 1). The score on the $\mathrm{Y}$-axis represents the number of trials taken to learn List 1. Participants who were short of 17 objects by the fourth learning trial were given a score of 5. Higher scores indicate poor learning performance. Control group $(M=3.13, S E M=0.13)$, unipolar group $(M=3.26, S E M=0.14)$, and bipolar group $(M=3.92, S E M=0.16)$. $(C)$ List 2 learning performance in Session 2. The score on the $\mathrm{Y}$-axis represents the number of trials taken to learn List 2. Participants who were short of 17 objects by the fourth learning trial were given a score of 5. Higher scores indicate poor learning performance. Control R $(M=2.58, S E M=0.12)$, control NR $(M=2.73, S E M=0.14)$, unipolar $\mathrm{R}(M=3.08, S E M=0.13)$, unipolar $\mathrm{NR}(M=2.78, S E M=0.16)$, bipolar R $(M=3.44, S E M=0.19)$, bipolar NR $(M=3.78, S E M=0.16) .(\mathrm{D})$ Mean List 1 recall performance in Session 3 across four recall trials. Control $\mathrm{R}(M=48.77, S E M=3.15)$, control NR $(M=52.21, S E M=3.48)$, unipolar R $(M=33.18, S E M=1.96)$, unipolar NR $(M=37.5, S E M$ $=2.57)$, bipolar $\mathrm{R}(M=30.9, S E M=2.03)$. $(\mathbf{E})$ Mean proportion of intrusions in List 1 recall in Session 3 across four recall trials. Control R $(M=36.24, S E M=3.4)$, control NR $(M=13.14, S E M=2.6)$, unipolar $\mathrm{R}(M=33.22, S E M=3.7)$, unipolar NR $(M=18.97, S E M=3.5)$, bipolar $\mathrm{R}(M=37.61, S E M=3.0)$, bipolar NR $(M=26.18, S E M=3.3)$. control group; unipolar group, $\quad$ bipolar group; R, Reminder condition (solid color bars); NR, No-Reminder condition (hashed bars). Error bars denote standard error of the mean. $* p \leq 0.05, * * p \leq 0.01$, and $* * * p \leq 0.001$.

\subsubsection{Does Unipolar or Bipolar Depression Affect List Learning?}

The number of trials taken by participants to recall at least 17 objects in Sessions 1 and 2 were recorded as a learning score, ranging between 1 and 4. Participants who recalled fewer than 17 objects during the fourth learning trial were given a score of 5 , which was indicative of a poorer performance than those who were able to learn at least 17 objects within the first 4 trials (Figure 1B-C). 
Learning of List 1 in Session 1: The learning scores for List 1 were analyzed using a 3 (control, unipolar, bipolar) x 2 (reminder, no-reminder) factorial ANOVA. The diagnostic group had a main effect on the learning score for List $1\left(F_{(2,135)}=8.34, M S E=1.02, p<0.001, \eta_{p}{ }^{2}=0.11\right)$. Post-hoc comparisons (Tukey) showed that the bipolar group needed more trials to learn List 1 than did the unipolar $(p=0.005)$ and control ( $p=0.001$ ) groups (Figure 1B). There was no difference in the learning score for List 1 between the unipolar and control groups $(p=0.8)$.

Since the testing conditions in Session 1 on Day 1 (Figure 1A) were the same for all diagnostic groups, the reminder condition, implemented two days later in Session 2, had no effect on the learning score for List $1(F<1)$. The interaction between diagnostic group and reminder condition also had no effect on the learning score for List $1(F<1)$.

Learning of List 2 in Session 2: The learning scores for List 2 were also analyzed using a 3 (control, unipolar, bipolar) x 2 (reminder, no-reminder) factorial ANOVA. The diagnostic group had a main effect on the learning score for List $2\left(F_{(2,135)}=10.7, M S E=1.07, p<0.001, \eta_{p}{ }^{2}=0.14\right)$. Post-hoc comparisons (Tukey) showed that the bipolar group took more trials to learn List 2 than the control $(p<0.001)$ and unipolar $(p<0.01)$ groups (Figure 1C). The learning score for List 2 did not differ between the control and unipolar groups $(p=0.38)$. Once again, the reminder condition had no effect on the learning score for List $2(F<1)$. The interaction between diagnostic group and reminder condition also had no effect on learning score for List $2(F<1)$.

Further, demographic measures (age, education), clinical measures (onset age, illness duration), or symptoms of depression or mania (HAMD, YMRS) did not correlate with the learning scores for List 1 or List 2.

Thus, based on results from Sessions 1 and 2 (Day 1 and Day 3, Figure 1B-C), the unipolar group learned the objects as quickly as the control group. The bipolar group, however, was less efficient and required more trials than the other groups to learn both lists. 


\subsubsection{Does Unipolar or Bipolar Depression Affect Recall?}

Each of the four recall trials in Session 3 was scored for List 1 recall (i.e. correctly recalled objects from List 1). The mean percent of List 1 objects recalled over 4 trials is shown in Figure 1D (Day 5, Session 3). Since these participants were specifically asked to recall items from List 1, but not List 2, we also measured the extent to which List 1 memory underwent updating due to the reminder condition on Day 3. Here updating is characterized by the spontaneous recall of objects from List 2, referred as 'intrusions'. The intrusions were not included in the calculations for List 1 recall and were analyzed separately.

Recall of List 1 in Session 3: The recall of List 1 was analyzed using 3 (control, unipolar, bipolar) x 2 (reminder, no-reminder) x 4 (recall trials: List 1) a mixed factorial ANOVA, with diagnostic group and reminder condition as between group variables and List 1 recall trial as within group variable. The diagnostic group had a main effect on the recall List $1\left(F_{(2,135)}=28.69, \mathrm{MSE}=1.35, p<0.001, \eta_{p}{ }^{2}=0.3\right)$. Posthoc comparisons (Tukey) revealed that the unipolar and bipolar groups recalled significantly fewer List 1 objects than the control group (both $p<0.001$, Figure 1D). There was no difference in the objects recalled between the unipolar and bipolar groups $(p=0.34)$. The reminder condition had no effect on the recall of List $1\left(F_{(1,135)}=2.05, p=0.15\right)$. The interaction between diagnostic group and reminder condition also had no effect on recall of List $1(F<1)$. The analysis also revealed a main effect of recall trial $\left(F_{(2.89 \text {, }}\right.$ $362.83=24.95, M S E=1.29 ; p<0.001, \eta_{p}{ }^{2}=0.16 ;$ Huynh-Feldt sphericity correction $)$. Within-subjects contrasts confirmed a linear trend of recall of List 1 objects over the four successive trials $\left(F_{(1,135)}=58.51\right.$, $\left.M S E=1.53, p<0.001, \eta_{p}{ }^{2}=0.3\right)$. Consecutive recall trials generally result in incremental recall of items which has been observed in previous studies (Hupbach et al., 2007; Tulving, 1964).

In order to emphasize the effect of diagnostic group on the recall of List 1, the mean recall of List 1 across 4 trials is plotted in Figure 1D. 
Intrusions into List 1 memory from List 2 (Session 3): Since recall of List 1 varied across groups, the absolute number of intrusions (items from List 2) provided limited information about the extent of updating. To take overall recall performance into account, a proportion of intrusions was calculated for every recall trial $\left[\right.$ proportion of intrusions $\left.=\{\text { intrusions } /(\text { intrusions }+ \text { List } 1 \text { recall })\}^{*} 100\right]$. The mean proportion of intrusions over 4 recall trials is summarized in Figure 1E (Session 3, Day 5).

The proportion of intrusions was analyzed using a 3 (control, unipolar, bipolar) x 2 (reminder, noreminder) x 4 (recall trials: proportion of intrusions) mixed factorial ANOVA. The reminder condition had a main effect on the proportion of intrusions $\left(F_{(1,135)}=35.04, M S E=0.1, p<0.001, \eta_{p}{ }^{2}=0.21\right)$ indicating that the proportion of intrusions were higher in the reminder groups than the respective no-reminder groups (Figure 1E). A trending main effect of diagnostic group on the proportion of intrusions was also observed $\left(F_{(2,135)}=2.58, p=0.07\right)$. The interaction between diagnostic group and reminder condition had no effect on the proportion of intrusions $\left(F_{(2,135)}=1.77, p=0.17\right)$. Once again, to emphasize the effect of diagnostic group on proportion of intrusions, the mean proportion of intrusions over 4 recall trials is plotted in Figure 1E.

Age, education, onset age, illness duration, or symptoms of depression or mania did not correlate with any measure of recall in Session 3. Eta squared correlations showed that mood stabilizers, antidepressant, antipsychotic, and anxiolytic drugs accounted for less than 5\% of the variance in learning and recall in unipolar and bipolar depression.

\subsection{Summary of Results from Experiment 1}

First, as expected, delayed recall of List 1 was impaired in unipolar and bipolar depression (Figure 1D). Second, the proportion of intrusions in unipolar and bipolar individuals that received a reminder was comparable to that of the control reminder group (Figure 1E). Strikingly, despite impaired recall of List 1, unipolar and bipolar groups apparently updated their memory for that list when it was reactivated 
through a reminder, at a rate that was comparable to control levels. This result suggests that the ability to update episodic memory remained unaffected in unipolar and bipolar groups.

We also made another observation which, however, did not reach statistical significance. Even in the absence of a reminder, the proportion of intrusions in the bipolar group was unexpectedly high (26\%), almost twice that of the control group (NR groups, Figure 1E). Further, it is interesting to note that the difference between the bipolar reminder vs no-reminder groups is much smaller (11\%) than the difference between control reminder vs no-reminder groups (23\%) (R vs NR, Figure 1E), suggesting that the reminder may have limited effects on updating in bipolar depression. In other words, the bipolar noreminder group appeared to be mixing items from List 2 with those from List 1, even though List 1 had not been reactivated when they were learning List 2. However, this interpretation calls for caution, and more investigation, because in the absence of statistical significance in the main effect this finding could not be subjected to further analysis in Experiment 1. Anecdotally as well, the bipolar depression patients frequently reported confusion between the lists during recall. They reported remembering items but were unable to limit their recall to the instructed list. We, therefore, probed this further in a new experiment using a separate cohort of control, unipolar, and bipolar participants (Experiment 2).

\subsection{Rationale for Testing Recall of List 2}

Typically, in an episodic memory updating paradigm, List 2 objects intrude into List 1 during later recall; this is contingent upon reactivation of List 1 before learning List 2. In contrast, List 1 objects do not intrude into List 2 recall because List 2 is learned later and is not reactivated once learned. In this sense, memory updating is 'unidirectional' (Hupbach et al. 2007). If bipolar patients indeed update List 1 independent of its reactivation, then List 2 recall might also show intrusions from List 1, indicating 'bidirectional' interference. Unlike memory updating, this pattern of difficulty in remembering which objects belong to which list reflects what is known as 'source confusion' (Johnson et al. 1993). 
Therefore, we next tested List 2 recall in Session 3 in a separate cohort of patients (Experiment 2, Figure 2A) to confirm unidirectional memory updating in unipolar patients and to further assess whether the trending bidirectional interference observed in Experiment 1 persists in bipolar patients. In other words, we expect to find intrusions from List 1 during List 2 recall in the bipolar patients but not in the unipolar patients or control group.

\subsection{Experiment 2}

Participants in Experiment 2 did not participate in Experiment 1. Participants were subjected to the same experimental procedures (Sessions 1/Day1 and Session 2/Day 3, Figure 2A) as described earlier

for Experiment 1 (Figure 1A). However, unlike Experiment 1, participants in Experiment 2 were asked to recall List 2 in Session 3 on Day 5 (Figure 2A). In Experiment 2, one bipolar patient was unwilling to complete Session 3 and was therefore excluded from the analysis. Statistical analysis revealed the same results for Sessions 1 and 2 (Figure 2A-C) as reported in Experiment 1. The results obtained from Experiment 2 are presented below. 


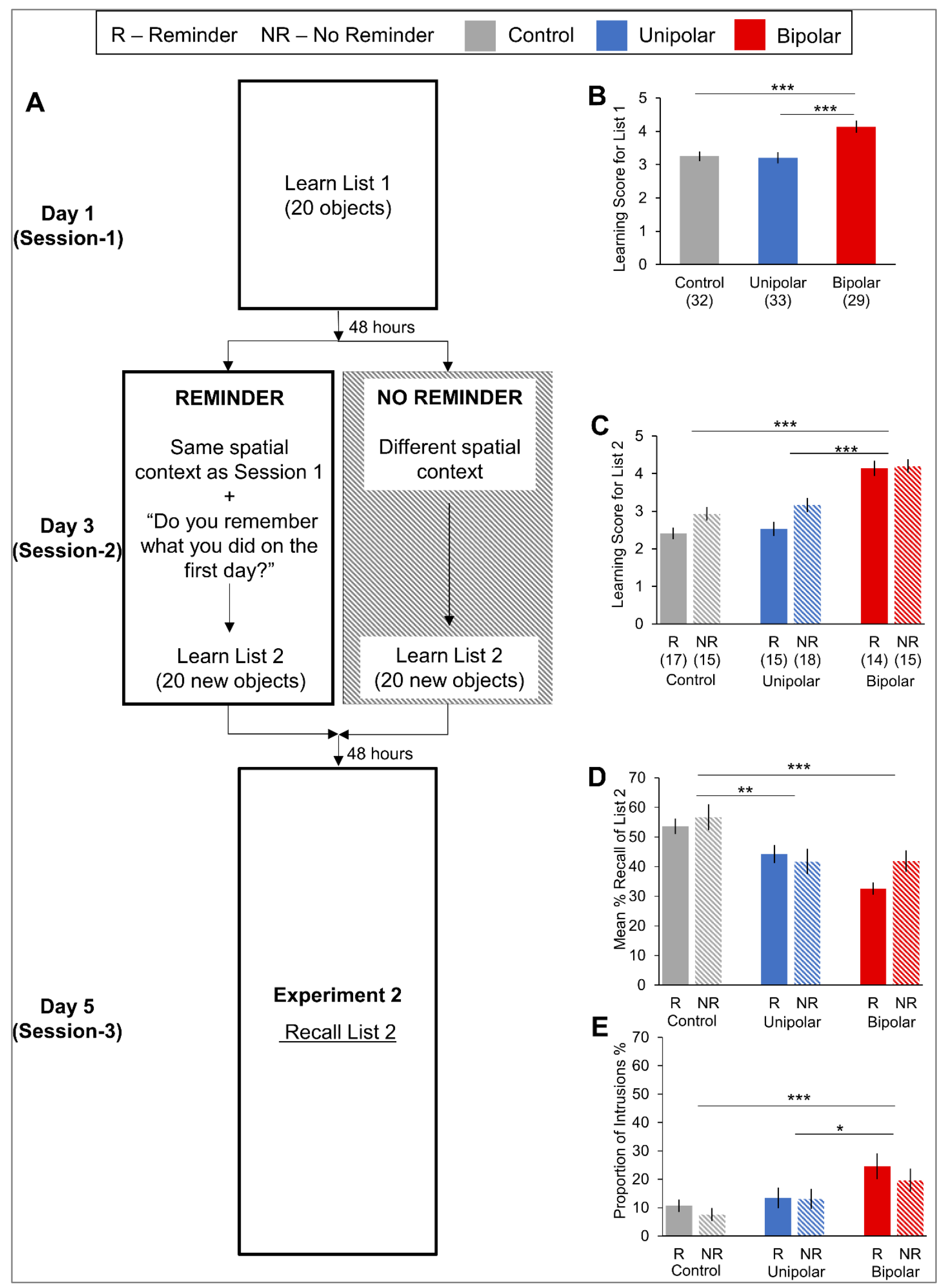


Figure 2. Effects of unipolar and bipolar depression on list learning and recall of List 2 (Experiment 2). (A) Experimental design spanning three sessions. (B) List 1 learning performance in Session 1 (Day 1). The score on the Y-axis represents the number of trials taken to learn List 1. Participants who were short of 17 objects by the fourth learning trial were given a score of 5. Higher scores indicate poor learning performance. Control group $(M=3.25, S E M=0.15)$, unipolar group $(M=3.21, S E M=0.17)$, and bipolar group $(M=4.14, S E M=0.18)(C)$ List 2 learning performance in Session 2. The score on the Y-axis represents the number of trials taken to learn List 2. Participants who were short of 17 objects by the fourth learning trial were given a score of 5 . Higher scores indicate poor learning performance. Control R $(M=2.41, S E M=0.16)$, control NR $(M=2.93, S E M=0.18)$, unipolar R $(M=2.53, S E M=0.19)$, unipolar NR $(M=3.16, S E M=0.18)$, bipolar R $(M=4.14, S E M=0.2)$, bipolar NR $(M=4.2, S E M=$ 0.18). (D) Mean List 2 recall performance in Session 3 across four recall trials. Control $\mathrm{R}(M=53.67$, $S E M=2.61)$, control NR $(M=56.67, S E M=4.42)$, unipolar R $(M=44.25, S E M=3.03)$, unipolar NR $(M$ = 41.74, SEM = 4.32), bipolar R $(M=32.59, S E M=2.1)$, bipolar NR $(M=41.83, S E M=3.6) .(\mathbf{E})$ Mean proportion of intrusions in List 2 recall in Session 3 across four recall trials. Control $\mathrm{R}(M=10.66, S E M=$ 2.17), control NR $(M=7.6, S E M=2.28)$, unipolar R $(M=13.44, S E M=3.69)$, unipolar NR $(M=13.07$, $S E M=3.52)$, bipolar R $(M=24.51, S E M=4.51)$, bipolar NR $(M=19.68, S E M=4.08) . \quad$ control group; unipolar group, $\quad$ bipolar group; R, Reminder condition (solid color bars); NR, NoReminder condition (hashed bars). Error bars denote standard error of the mean. ${ }^{*} p \leq 0.05,{ }^{* *} p \leq 0.01$, and $* * * p \leq 0.001$

\subsubsection{Does Unipolar or Bipolar Depression Affect List Learning?}

Learning of List 1 in Session 1: The learning scores for List 1 were analyzed with a 3 (control, unipolar, bipolar) $\mathrm{x} 2$ (reminder, no-reminder) factorial ANOVA. The diagnostic group had a main effect on the 
learning score for List $1\left(F_{(2,88)}=9.89, M S E=0.83, p<0.001, \eta_{p}{ }^{2}=0.18\right)$. A post-hoc test for unequal variances (Gabriel) showed that the bipolar group took more trials to learn List 1 than the unipolar group $(p<0.001)$ and control group $(p=0.001)$ (Figure 2B). There was no difference in the learning score for List 1 between the unipolar and control groups $(p=0.99)$. Neither reminder condition $\left(F_{(1,88)}=3.66, M S E=0.83\right.$, $\left.p=0.06, \eta_{p}{ }^{2}=0.05\right)$ nor the interaction had any effect on the learning score for List $1\left(F^{\prime} s^{<}<1\right)$.

Learning of List 2 in Session 2: The learning scores for List 2 were analyzed with a 3 (control, unipolar, bipolar) x 2 (reminder, no-reminder) factorial ANOVA. The diagnostic group had a main effect on the learning score for List $2\left(F_{(2,88)}=18.94, \mathrm{MSE}=1.06, \mathrm{p}<0.001, \eta_{p}{ }^{2}=0.3\right)$. Post-hoc comparisons (Gabriel) revealed that the bipolar group took more trials to learn List 2 than did the control group $(p<0.001)$ and unipolar group $(p<0.001$, Figure $2 \mathrm{C})$. There was no difference in the learning score for List 2 between unipolar and control groups $(p=0.76)$. Neither the reminder condition $\left(F_{(1,88)}=3.58, M S E=1.06, p=0.06\right.$, $\left.\eta_{p}{ }^{2}=0.04\right)$ nor the interaction had any effect on the learning score for List $2(F<1)$.

Thus, bipolar patients were consistently less efficient at learning both lists.

\subsubsection{Does Unipolar or Bipolar Depression Affect Recall?}

This time, each of the four recall trials during Session 3 was scored for List 2 recall (correctly recalled objects from List 2) and proportion of intrusions (spontaneously recalled objects from List 1).

Recall of List 2 in Session 3: The recall of List 2 was analyzed with a 3 (control, unipolar, bipolar) x 2 (reminder, no-reminder) x 4 (recall trials: List 2) mixed factorial ANOVA with diagnostic group and reminder condition as between group variables and List 2 recall trial as within group variable. The diagnostic group had a main effect on recall of List $2\left(F_{(2,88)}=13.29, M S E=31.16, p<0.001, \eta_{p}{ }^{2}=0.23\right)$. Post-hoc comparisons (Gabriel) revealed that unipolar $(p=0.002)$ and bipolar $(p<0.001)$ groups recalled 
significantly fewer List 2 objects than the control group (Figure 2D). There was no difference in the number of List 2 objects recalled between unipolar and bipolar groups $(p=0.33)$. There was no effect of reminder condition on recall of List $2\left(F_{(1,88)}=1.26, p=0.26\right)$. There was no interaction between diagnostic group and reminder condition on recall of List $2\left(F_{(2,88)}=1.36, p=0.26\right)$.

Additionally, a main effect of recall trial was observed $\left(F_{(2.8,250.91)}=17.4, M S E=1.33, p<0.001\right.$, $\eta_{p}{ }^{2}=0.16$; Huynh-Feldt sphericity correction). Within-subjects contrasts confirmed a linear trend in recall of objects from List 2 over the four recall trials $\left(F_{(1,88)}=38.37, M S E=1.68, p<0.001, \eta_{p}{ }^{2}=0.3\right)$. To highlight the effect of diagnostic group on the recall of List 2, the mean recall of List 2 over four recall trials is plotted in Figure 2D.

Intrusions into List 2 memory from List 1 (Session 3): Once again, as recall of List 2 varied across groups, the absolute number of intrusions from List 1 provided limited information about the extent of updating. Therefore, a proportion of intrusions was computed for every recall trial, as done in Experiment 1.

The proportion of intrusions in recall of List 2 was analyzed with a 3 (control, unipolar, bipolar) $\mathrm{x}$ 2 (reminder, no-reminder) x 4 (recall trials: proportion of intrusions) mixed factorial ANOVA. The diagnostic group had a main effect on the proportion of intrusions during recall of List $2\left(F_{(2,88)}=7.15\right.$, $\left.M S E=738.66, p=0.001, \eta_{p}{ }^{2}=0.14\right)$. As expected, post-hoc comparisons (Gabriel) revealed a higher proportions of intrusions in the bipolar group in comparison to the control group $(p=0.001)$ and the unipolar group $(p=0.038$ ) (Figure 2E). There was no difference in the proportion of intrusions between unipolar and control groups $(p=0.55)$. Neither the reminder condition nor the interaction between the reminder condition and diagnostic group had any effect on the proportion of intrusions in recall of List 2 $\left(F^{\prime} s<1\right)$. Once again, to emphasize the effect of diagnostic group on proportion of intrusions, the mean proportion of intrusions across four recall trials is plotted in Figure 2E. 
Age, education, onset age, illness duration, or symptoms of depression or mania did not correlate with learning or recall. Eta squared correlations showed that antidepressants accounted for $11 \%$ of the variance in List 1 learning and 16\% of the variance in List 2 learning in bipolar patients. Anti-psychotics accounted for $17 \%$ of the variance in List 1 learning in unipolar patients. Mood stabilizers and antianxiety medication accounted for less than $5 \%$ of the variance in learning and recall in unipolar and bipolar depression.

Thus, Experiment 2 confirmed that unidirectional updating occurs in unipolar depression while bidirectional interference persists in bipolar depression.

\section{Discussion}

This study examined episodic memory updating in unipolar and bipolar depression. Consistent with previous findings (Airaksinen et al. 2004; Austin et al. 1992; Bearden et al. 2006a, b; Fossati et al. 2004; Kizilbash et al. 2002; Pauls et al. 2015; Sweeney et al. 2000; Van Gorp et al. 1999), delayed recall of episodic content, after four days, was impaired in both unipolar and bipolar depression (Figure 3). Surprisingly, despite this impairment in recall, the ability to update a reactivated memory was not impaired in unipolar depression patients. Bipolar patients were distinct in this regard - mixing of memories was indiscriminate. In other words, irrespective of reactivation, items from the two lists interfered with each other during recall in bipolar patients (Figure 3). Thus, a more nuanced assessment of memory, by evaluating selective memory updating, offers a new way of distinguishing unipolar from bipolar depression. 


\begin{tabular}{|c|c|c|c|c|c|}
\hline & \multirow{2}{*}{$\begin{array}{l}\text { List } \\
\text { Learning }\end{array}$} & \multirow{2}{*}{$\begin{array}{l}\text { Delayed } \\
\text { Recall }\end{array}$} & \multicolumn{2}{|c|}{ Episodic Memory Updating } & \multirow{2}{*}{$\begin{array}{l}\text { Direction of } \\
\text { Updating }\end{array}$} \\
\hline & & & Reminder & No Reminder & \\
\hline Control & & & \multirow{2}{*}{$\begin{array}{l}\text { List } 1 \leftarrow \text { List } 2(\operatorname{Exp} 1) \\
\text { List } 1 \rightarrow \text { List } 2(\operatorname{Exp} 2)\end{array}$} & \multirow{2}{*}{$\begin{array}{l}\text { List 1 L List } 2 \text { (든 1) } \\
\text { List 1 } \rightarrow \text { List } 2 \text { (Exp 2) } \\
\text { No updating }\end{array}$} & \multirow{2}{*}{ Unidirectional } \\
\hline Unipolar & $\checkmark$ & & & & \\
\hline Bipolar & & & 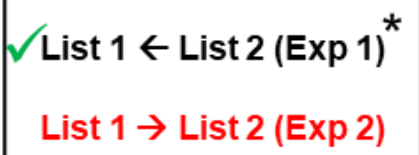 & $\begin{array}{l}\text { List 1 L List 2 (Exp 1) } \\
\text { List } 1 \rightarrow \text { List } 2(\operatorname{Exp} 2)\end{array}$ & Bidirectional \\
\hline
\end{tabular}

Figure 3. Summary of key findings. List learning was intact in unipolar patients whereas bipolar patients took more trials to learn both lists. Delayed recall was impaired in both unipolar and bipolar patients. Episodic memory updating was unidirectional and intact in unipolar patients. Bipolar patients, in contrast, showed a bidirectional interference pattern between the lists. Normal outcomes compared to the control group, abnormal outcomes. *Bipolar reminder participants, together from Experiment 1 and 2, exhibit bidirectional intrusions (List $1 \leftarrow$ List 2 and List $1 \rightarrow$ List 2). Similar effects did not reach statistical significance in bipolar no-reminder participants in Experiment 1, but the reactivationindependent intrusions, in the reverse order (List $1 \rightarrow$ List 2), were seen in Experiment 2. Please refer to the description of Experiment 1 results (Section 3.2) for additional details.

\subsection{Slower Learning in Bipolar Depression}

While learning was not affected in unipolar patients, bipolar patients were slower to learn both lists, reflecting difficulties in encoding. Earlier studies reported that deficits in sustained attention (Clark et al. 2002), encoding (Bearden et al. 2006a; Deckersbach et al. 2004, 2006), executive function and working memory (Lagopoulos et al. 2007; Monks et al. 2004) are common in the depressive or mania phases of bipolar illness (Martínez-Arán et al. 2004; Vrabie et al. 2015), and may underlie the learning deficits 
reported here. On the other hand, it has been reported that unipolar depression has minimal effect on attention (Harvey et al. 2004; Liu et al. 2002) and working memory (Matsuo et al. 2007; Purcell et al. 1998). Overall, neuropsychological functions are reported to be more impaired in bipolar than unipolar depression (Borkowska and Rybakowski 2001).

\subsection{Impaired Recall in both Unipolar and Bipolar Depression}

During list recall, unipolar and bipolar patients generally recalled fewer items. This deficient recollection in bipolar patients might arise from deficits in encoding. Neuroimaging studies have observed that decreased activity in the dorsal and ventral prefrontal regions in bipolar disorder patients is accompanied by deficits in encoding (Hall et al. 2010; Phillips and Vieta 2007; Strakowski et al. 2004), which subsequently may impair recall. Interestingly, unipolar patients also showed impaired recall for both lists despite intact learning. This deficit in recollection might be a consequence of impaired consolidation (Nissen et al. 2010) resulting from altered hippocampal function in unipolar depression (Campbell and MacQueen 2003; Sheline et al. 2002). Deficits in recollection are common in both unipolar and bipolar depression and our findings are consistent with these earlier reports (Bearden et al. 2006b; Sweeney et al. 2000).

\subsection{Episodic Memory Updating in Unipolar Depression: Functional and Unidirectional}

Reactivation opens a memory representation to modification. Concurrent experiences can update the contents of that reactivated memory. Notably, despite an impairment in recall, the ability to update a reactivated memory (List 1) with items from a subsequently learned List 2 was unaffected in unipolar depression. The non-reactivated memory (List 2) did not undergo updating, indicating normal 'unidirectional' memory updating in unipolar depression.

Neuroimaging data suggest that hippocampal-prefrontal interaction is crucial for reactivating episodic experiences (Cabeza and Nyberg 2000; Nyberg et al. 1996) ), maintaining their active state (Cohen et al., 1997), and integrating subsequent learning (Schlichting and Preston 2016). Although 
functional impairments have been observed in these brain regions in depression, reactivation-dependent memory updating in our paradigm appears to be unaffected. This raises an important question about the potential role of contextual or spatial information in such tasks. Updating in the episodic memory task used here is critically dependent on learning both lists in the same spatial context (Hupbach et al., 2008). Hartlage et al. (1993) reported that physical space can be encoded or retrieved even with limited attentional resources. Such automatic processing of information is minimally affected by depression whereas effortful processing can be dampened by depression (Hartlage et al. 1993). Processing that requires effort, such as recollecting details of an event or objects in a list, can be readily affected by depression. On the other hand, automatic processing, such as context-dependent reactivation, seems less affected. Future studies will be needed to elucidate the extent to which depression can impact contextual information processing.

\subsection{Episodic Memory Updating in Bipolar Depression: Bidirectional Interference}

In bipolar patients, irrespective of reactivation, recall of either list revealed interference from the other list. This bidirectional interference pattern may reflect a source discrimination problem, rather than a memory updating process. In other words, bipolar patients may be susceptible to such interference effects resulting from defective encoding of the contexts in which events occur, making it easier to confuse one list with the other at the time of recall. This is in line with studies showing that source monitoring requires dorsal and ventral prefrontal activity (Blumenfeld and Ranganath 2007; Mitchell and Johnson 2009), which has been observed to be consistently affected in bipolar patients (Deckersbach et al. 2006; Hall et al. 2010; Lagopoulos et al. 2007; Monks et al. 2004; Phillips and Vieta, 2007). Further testing of bipolar depression patients using source monitoring paradigms can explore these issues.

Other work on source monitoring has suggested that these prefrontal sub-regions also monitor the source of perceived and imagined events (Johnson et al. 1993, 1997; Turner et al. 2008). Thus, it would be interesting to investigate, in the context of seminal studies in the field (Johnson et al. 1993, 
1997), if source monitoring deficits can explain hallucinations, a sporadic symptom observed in bipolar illness.

\subsection{Relevance to Current Behavioral Interventions}

There is growing interest in using reactivation-dependent memory updating as a therapeutic intervention for a range of psychiatric conditions (Beckers and Kindt 2017; Lee et al. 2017). Our results suggest that the efficacy of such an intervention may vary between cases with comorbid unipolar or bipolar depression. For instance, Post-Traumatic Stress Disorder (PTSD) and other anxiety disorders are often found to be comorbid with unipolar (Biehn et al. 2013; Fava et al. 2000; Murrough et al. 2011; Rauch et al. 2010) or bipolar depression (Assion et al. 2009; Hernandez et al. 2013; Otto et al. 2004; Simon et al. 2004). In reactivation-dependent behavioral therapy for PTSD, once a traumatic or stressful memory is reactivated, the individual is oriented to neutral or positive information, thereby overwriting the stressful memory (Gray and Bourke 2015; Gray and Liotta 2012). Compared to unipolar patients, bipolar patients might not benefit from such paradigms to the same extent since they consistently showed underlying problems in learning, recall, and updating. Thus, screening individuals for comorbid bipolar illness might help to enhance the success of reactivation-based interventions.

\subsection{Limitations}

All patients continued taking their medications while participating in the study. Although we found no effects of medication on learning or recall in Experiment 1, we observed small effects of anti-depressants and anti-psychotics on list learning but not recall in Experiment 2. Given that in-patients are typically on medication and discontinuing their treatment for research is unethical, these effects could be overridden with a larger sample size.

\section{Conclusions}


Our findings using a paradigm involving reactivation-dependent memory updating revealed a distinction between unipolar versus bipolar depression. This underscores the importance of utilizing the growing body of experimental evidence from animal and human studies on learning and memory to evaluate corresponding deficits in clinical populations. Such strategies, in turn, are likely to provide further insights into the debilitating impacts of depression on memory processes.

\section{Acknowledgements}

We thank Dr. Sanjeev Jain \& Dr. Biju Viswanath for providing access to patients at NIMHANS, and their support and advice. We also thank all participants who consented to participate.

\section{Author Contributions}

BD and SC conceptualized the study. BD administered the protocol on patients. BD and AH performed statistical analyses. All authors wrote and reviewed the manuscript.

\section{Role of the Funding Source}

This study was supported by the Department of Biotechnology Research Associateship awarded to BD. The Council of Scientific and Industrial Research and Infosys Foundation provided travel support to BD to present this work at scientific meetings. This work was also supported by funds from the Madan and Usha Sethi Fellowship awarded to SC.

\section{Conflict of Interest}

The authors declare no biomedical financial interests or potential conflicts of interest. 


\section{References}

Assion, H.J., Brune, N., Schmidt, N., Aubel, T., Edel, M.A., Basilowski, M., Juckel, G., Frommberger, U. (2009). Trauma exposure and post-traumatic stress disorder in bipolar disorder. Social Psychiatry Psychiatric Epidemiology, 44, 1041-1049.

Austin, M.P., Ross, M., Murray, C., O’Caŕroll, R.E., Ebmeier, K.P., Goodwin, G.M., 1992. Cognitive function in major depression. J. Affect. Disord. 25, 21-29. https://doi.org/10.1016/01650327(92)90089-O

Bearden, C.E., Glahn, D.C., Monkul, E.S., Barrett, J., Najt, P., Kaur, S., Sanches, M., Villarreal, V., Bowden, C., Soares, J.C., 2006a. Sources of declarative memory impairment in bipolar disorder: Mnemonic processes and clinical features. J. Psychiatr. Res. 40, 47-58. https://doi.org/10.1016/j.jpsychires.2005.08.006

Bearden, C.E., Glahn, D.C., Monkul, E.S., Barrett, J., Najt, P., Villarreal, V., Soares, J.C., 2006b. Patterns of memory impairment in bipolar disorder and unipolar major depression. Psychiatry Res. 142, 139150. https://doi.org/10.1016/j.psychres.2005.08.010

Beckers, T., Kindt, M., 2017. Memory Reconsolidation interference as an emerging treatment for emotional disorders: strengths, limitations, challenges, and opportunities. Annu Rev Clin Psychol 13:99-121. https://doi.org/10.1146/annurev-clinpsy-032816-045209

Biehn, T.L., Contractor, A., Elhai, J.D., Tamburrino, M., Fine, T.H., Prescott, M.R., Shirley, E., Chan, P.K., Slembarski, R., Liberzon, I., Calabrese, J.R., Galea, S., 2013. Relations between the underlying dimensions of PTSD and major depression using an epidemiological survey of deployed Ohio National Guard soldiers. J. Affect. Disord. 144, 106-111.

https://doi.org/10.1016/j.jad.2012.06.013

Bledowski, C., Rahm, B., Rowe, J.B., 2009. What "Works" in Working Memory? Separate systems for selection and updating of critical information. J. Neurosci. 29, 13735-13741. https://doi.org/10.1523/JNEUROSCI.2547-09.2009

Blumberg, H.P., Kaufman, J., Martin, A., Whiteman, R., Zhang, J.H., Gore, J.C., Charney, D.S., Krystal, J.H., Peterson, B.S., 2003. Amygdala and Hippocampal Volumes in Adolescents and Adults with Bipolar Disorder. Arch. Gen. Psychiatry 60, 1201-1208. https://doi.org/10.1001/archpsyc.60.12.1201

Blumenfeld, R.S., Ranganath, C., 2007. Prefrontal cortex and long-term memory encoding: An integrative review of findings from neuropsychology and neuroimaging. Neuroscientist 13, 280291. https://doi.org/10.1177/1073858407299290

Bödecs, T., Szilágyi, E., Cholnoky, P., Sándor, J., Gonda, X., Rihmer, Z., Horváth, B., 2013. Prevalence and psychosocial background of anxiety and depression emerging during the first trimester of pregnancy: Data from a Hungarian population-based sample. Psychiatr. Danub. 25, 352-358. https://doi.org/10.1080/00102200108907853

Borkowska, A., Rybakowski, J.K., 2001. Neuropsychological frontal lobe tests indicate that bipolar depressed patients are more impaired than unipolar. Bipolar Disord. 3, 88-94. https://doi.org/10.1034/j.1399-5618.2001.030207.x

Born, J., Wilhelm, I., 2012. System consolidation of memory during sleep. Psychol. Res. 76, 192-203. https://doi.org/10.1007/s00426-011-0335-6

Bremner, J.D., Vythilingam, M., Vermetten, E., Afzal, N., Nazeer, A., Newcomer, J.W., Charney, D.S., 
2004. Effects of dexamethasone on declarative memory function in posttraumatic stress disorder. Psychiatry Res. 129, 1-10. https://doi.org/10.1016/j.psychres.2004.08.004

Cabeza, R., Nyberg, L., 2000. Imaging cognition II: An empirical review of 275 PET and fMRI studies. J. Cogn. Neurosci. 12, 1-47.

Campbell, S., MacQueen, G., 2003. The role of the hippocampus in the pathophysiology of major depression. J. Psychiatry Neurosci. 29, 417-426. https://doi.org/S0143-4179(09)00069-9 [pii]ไr10.1016/j.npep.2009.06.004

Clark, L., Iversen, S.D., Goodwin, G.M., 2002. Sustained attention deficit in bipolar disorder. British J Psychiatry 180, 313-319.

Cohen, J.D., Perlstein, W.M., Braver, T.S., Nystrom, L.E., Noll, D.C., Jonides, J., Smith, E.E., 1997. Temporal dynamics of brain activation during a working memory task. Nature 386, 604.

Cotter, D., Mackay, D., Chana, G., Beasley, C., Landau, S., Everall, I.P., 2002. Reduced neuronal size and glial cell density in area 9 of the dorsolateral prefrontal cortex in subjects with major depressive disorder. Cerebral Cortex, 12, 386-394.

Das, R.K., Lawn, W., Kamboj, S.K., 2015. Rewriting the valuation and salience of alcohol-related stimuli via memory reconsolidation. Transl. Psychiatry 5, e645-9. https://doi.org/10.1038/tp.2015.132

Deckersbach, T., Dougherty, D.D., Savage, C., McMurrich, S., Fischman, A.J., Nierenberg, A., Sachs, G., Rauch, S.L., 2006. Impaired recruitment of the dorsolateral prefrontal cortex and hippocampus during encoding in bipolar disorder. Biol. Psychiatry 59, 138-146. https://doi.org/10.1016/j.biopsych.2005.06.030

Deckersbach, T., Savage, C.R., Reilly-Harrington, N., Clark, L., Sachs, G., Rauch, S.L., 2004. Episodic memory impairment in bipolar disorder and obsessive-compulsive disorder: The role of memory strategies. Bipolar Disord. 6, 233-244. https://doi.org/10.1111/j.1399-5618.2004.00118.x

Drevets, W.C., Öngür, D., Price, J.L., 1998. Neuroimaging abnormalities in the subgenual prefrontal cortex: Implications for the pathophysiology of familial mood disorders. Mol. Psychiatry 3, 220 226. https://doi.org/10.1038/sj.mp.4000370

Drevets, W.C., Price, J.L., Simpson Jr, J.R., Todd, R.D., Reich, T., Vannier, M., Raichle, M.E., 1997. Subgenual prefrontal cortex abnormalities in mood disorders. Nature, 386, 824.

Eldridge, L.L., Knowlton, B.J., Furmanski, C.S., Bookheimer, S.Y., Engel, S.A. 2000. Remembering episodes: A selective role for the hippocampus during retrieval. Nature Neurosci. 3, 1149.

Fava, M., Rankin, M.A., Wright, E.C., Alpert, J.E., Nierenberg, A.A., Pava, J., Rosenbaum, J.F., 2000. Anxiety disorders in major depression. Compr. Psychiatry 41, 97-102. https://doi.org/10.1016/S0010-440X(00)90140-8

Fossati, P., Harvey, P.O., Le Bastard, G., Ergis, A.M., Jouvent, R., Allilaire, J.F., 2004. Verbal memory performance of patients with a first depressive episode and patients with unipolar and bipolar recurrent depression. J. Psychiatr. Res. 38, 137-144. https://doi.org/10.1016/j.jpsychires.2003.08.002

Goldberg, D.P., Hillier, V.F., 1979. A scaled version of the General Health Questionnaire. Psychol. Med. 9, 139-145.

Gray, R.M., Bourke, F., 2015. Remediation of intrusive symptoms of PTSD in fewer than five sessions: a 30-person pre-pilot study of the RTM Protocol. J Military Veteran Family Health 1(2):13-20. 
https://doi.org/10.3138/jmvfh.2996

Gray, R.M., Liotta, R.F., 2012. PTSD : Extinction, reconsolidation , and the visual-kinesthetic dissociation protocol. Traumatology 18(2):3-16. https://doi.org/10.1177/1534765611431835

Hall, J., Whalley, H.C., Marwick, K., McKirdy, J., Sussmann, J., Romaniuk, L., Johnstone, E.C., Wan, H.I., McIntosh, A.M., Lawrie, S.M., 2010. Hippocampal function in schizophrenia and bipolar disorder. Psychol. Med. 40, 761-770. https://doi.org/10.1017/S0033291709991000

Hamilton, M. (1960): A rating scale for depression. J. Neurol. Neurosurgery Psychiatry 23, 56.

Hartlage, S., Alloy, L.B., Vázquez, C., Dykman, B., 1993. Automatic and effortful processing in depression. Psychol Bulletin 113, 247-278.

Harvey, P.O., Le Bastard, G., Pochon, J.B., Levy, R., Allilaire, J.F., Dubois, B., Fossati, P., 2004. Executive functions and updating of the contents of working memory in unipolar depression. $\mathrm{J}$. Psychiatr. Res. 38, 567-576. https://doi.org/10.1016/j.jpsychires.2004.03.003

Haubrich, J., Crestani, A.P., Cassini, L.F., Santana, F., Sierra, R.O., De O. Alvares, L., Quillfeldt, J.A., 2015. Reconsolidation allows fear memory to be updated to a less aversive level through the incorporation of appetitive information. Neuropsychopharmacology 40, 315-326. https://doi.org/10.1038/npp.2014.174

Haukvik, U.K., Westlye, L.T., Mørch-Johnsen, L., Jørgensen, K.N., Lange, E.H., Dale, A.M., Melle, I., Andreassen, O.A., Agartz, I., 2015. In vivo hippocampal subfield volumes in schizophrenia and bipolar disorder. Biol. Psychiatry 77, 581-588. https://doi.org/10.1016/j.biopsych.2014.06.020

Hermanns, N., Kulzer, B., Krichbaum, M., Kubiak, T., Haak, T., 2005. Affective and anxiety disorders in a German sample of diabetic patients: Prevalence, comorbidity and risk factors. Diabet. Med. 22, 293-300. https://doi.org/10.1111/j.1464-5491.2005.01414.x

Hernandez, J.M., Cordova, M.J., Ruzek, J., Reiser, R., Gwizdowski, I.S., Suppes, T., Ostacher, M.J., 2013. Presentation and prevalence of PTSD in a bipolar disorder population : A STEP-BD examination. J. Affect. Disord. 150, 450-455. https://doi.org/10.1016/j.jad.2013.04.038

Huang, Y., Coupland, N.J., Lebel, R.M., Carter, R., Seres, P., Wilman, A.H., Malykhin, N. V., 2013. Structural changes in hippocampal subfields in major depressive disorder: A high-field magnetic resonance imaging study. Biol. Psychiatry 74, 62-68. https://doi.org/10.1016/j.biopsych.2013.01.005

Hupbach, A., Gomez, R., Hardt, O., Nadel, L., 2007. Reconsolidation of episodic memories: A subtle reminder triggers integration of new information. Learn. Mem. 14, 47-53. https://doi.org/10.1101/lm.365707

Hupbach, A., Hardt, O., Gomez, R., Nadel, L., 2008. The dynamics of memory: Context-dependent updating. Learn. Mem. 15, 574-579. https://doi.org/10.1101/lm.1022308

Johnson, M.K., Hashtroudi, S., Lindsay, D.S., 1993. Source monitoring. Psychol. Bulletin 114, 3-28.

Johnson, M.K., Kounios, J., Nolde, S.F., 1997. Electrophysiological brain activity and memory source monitoring. Neuroreport 8, 1317-1320. https://doi.org/10.1097/00001756-199703240-00051

Kizilbash, A.H., Vanderploeg, R.D., Curtiss, G., 2002. The effects of depression and anxiety on memory performance. Arch. Clin. Neuropsychol. 17, 57-67. https://doi.org/10.1016/S0887-6177(00)00101-3

Konradi, C., Zimmerman, E.I., Yang, C.K., Lohmann, K.M., Gresch, P., Pantazopoulos, H., Berretta, S., Heckers, S., 2011. Hippocampal interneurons in bipolar disorder. Arch. Gen. Psychiatry 68, 340- 
350. https://doi.org/10.1001/archgenpsychiatry.2010.175

Lagopoulos, J., Ivanovski, B., Malhi, G.S., 2007. An event-related functional MRI study of working memory in euthymic bipolar disorder. J Psychiatry Neurosci 32, 174-184.

Lee, J.L.C., 2008. Memory reconsolidation mediates the strengthening of memories by additional learning. Nat. Neurosci. 11, 1264-1266. https://doi.org/10.1038/nn.2205

Lee, J.L.C., Nader, K., Schiller, D., 2017. An Update on Memory Reconsolidation Updating. Trends Cogn. Sci. 21, 531-545. https://doi.org/10.1016/j.tics.2017.04.006

Liu, S.K., Chiu, C.H., Chang, C.J., Hwang, T.J., Hwu, H.G., Chen, W.J., 2002. Deficits in sustained attention in schizophrenia and affective disorders: Stable versus state-dependent markers. Am. J. Psychiatry 159, 975-982. https://doi.org/10.1176/appi.ajp.159.6.975

Marshall, L., Born, J., 2007. The contribution of sleep to hippocampus-dependent memory consolidation. Trends Cogn. Sci. 11, 442-450. https://doi.org/10.1016/j.tics.2007.09.001

Martínez-Arán, A., Vieta, E., Reinares, M., Colom, F., Torrent, C., Sánchez-Moreno, J., Benabarre, A., Goikolea, J.M., Comes, M., Salamero, M., 2004. Cognitive Function Across Manic or Hypomanic, Depressed, and Euthymic States in Bipolar Disorder. Am. J. Psychiatry 161, 262-270. https://doi.org/10.1176/appi.ajp.161.2.262

Matsuo, K., Glahn, D.C., Peluso, M.A.M., Hatch, J.P., Monkul, E.S., Najt, P., Sanches, M., Zamarripa, F., Li, J., Lancaster, J.L., Fox, P.T., Gao, J.H., Soares, J.C., 2007. Prefrontal hyperactivation during working memory task in untreated individuals with major depressive disorder. Mol. Psychiatry 12, 158-166. https://doi.org/10.1038/sj.mp.4001894

Mitchell, K.J., Johnson, M.K., 2009. Source Monitoring 15 Years Later: What Have We Learned From fMRI About the Neural Mechanisms of Source Memory? Psychol. Bull. 135, 638-677. https://doi.org/10.1037/a0015849

Monks, P.J., Thompson, J.M., Bullmore, E.T., Suckling, J., Brammer, M.J., Williams, S.C.R., Simmons, A., Giles, N., Lloyd, A.J., Harrison, C.L., Seal, M., Murray, R.M., Ferrier, I.N., Young, A.H., Curtis, V.A., 2004. A functional MRI study of working memory task in euthymic bipolar disorder: Evidence for task-specific dysfunction. Bipolar Disord. 6, 550-564. https://doi.org/10.1111/j.13995618.2004.00147.x

Murrough, J.W., Huang, Y., Hu, J., Henry, S., Williams, W., Gallezot, J.D., Bailey, C.R., Krystal, J.H., Carson, R.E., Neumeister, A., 2011. Reduced amygdala serotonin transporter binding in posttraumatic stress disorder. Biol. Psychiatry 70, 1033-1038. https://doi.org/10.1016/j.biopsych.2011.07.003

Nadel, L., Samsonovich, A., Ryan, L., Moscovitch, M., 2000. Multiple trace theory of human memory: Computational, neuroimaging, and neuropsychological results. Hippocampus 10, 352-368. https://doi.org/10.1002/1098-1063(2000)10:4<352::AID-HIPO2>3.0.CO;2-D

Nader, K., Schafe, G.E., LeDoux, J.E., 2000. Fear memories require protein synthesis in the amygdala for reconsolidation after retrieval. Nature 406, 722-726. https://doi.org/10.1038/35021052

Nissen, C., Holz, J., Blechert, J., Feige, B., Riemann, D., Voderholzer, U., Normann, C., 2010. Learning as a model for neural plasticity in major depression. Biol. Psychiatry 68, 544-552. https://doi.org/10.1016/j.biopsych.2010.05.026

Nyberg, L., Habib, R., McIntosh, A.R., Tulving, E., 2000. Reactivation of encoding-related brain activity during memory retrieval. Proc. Natl. Acad. Sci. 97, 11120-11124. 
Nyberg, L., Mclntosh, A.R., Houle, S., Nilsson, L.G., Tulving, E., 1996. Activation of medial temporal structures during episodic memory retrieval. Nature 380, 715-717.

Olshavsky, M.E., Song, B.J., Powell, D.J., Jones, C.E., Monfils, M.-H., Lee, H.J., 2013. Updating appetitive memory during reconsolidation window: critical role of cue-directed behavior and amygdala central nucleus. Front. Behav. Neurosci. 7, 1-14.

https://doi.org/10.3389/fnbeh.2013.00186

Otto, M.W., Perlman, C.A., Wernicke, R., Reese, H.E., Bauer, M.S., Pollack, M.H., 2004. Posttraumatic stress disorder in patients with bipolar disorder: A review of prevalence, correlates, and treatment strategies. Bipolar Disord 6, 470-479.

Pauls, F., Petermann, F., Lepach, A.C., 2015. Episodic memory and executive functioning in currently depressed patients compared to healthy controls. Cog Emotion 29, 383-400.

Phillips, M.L., Vieta, E., 2007. Identifying functional neuroimaging biomarkers of bipolar disorder: Toward DSM-V. Schizophr. Bull. 33, 893-904. https://doi.org/10.1093/schbul/sbm060

Purcell, R., Maruff, P., Kyrios, M., Pantelis, C., 1998. Neuropsychological deficits in obsessivecompulsive disorder: a comparison with unipolar depression, panic disorder, and normal controls. Arch. Gen. Psychiatry 55, 415-423.

Rajkowska, G., 2000. Postmortem studies in mood disorders indicate altered numbers of neurons and glial cells. Biol. Psychiatry 48, 766-777. https://doi.org/10.1016/S0006-3223(00)00950-1

Rajkowska, G., Miguel-Hidalgo, J.J., Wei, J., Dilley, G., Pittman, S.D., Meltzer, H.Y., Overholser, J.C., Roth, B.L., Stockmeier, C.A., 1999. Morphometric evidence for neuronal and glial prefrontal cell pathology in major depression. Biol. Psychiatry 45, 1085-1098. https://doi.org/10.1016/S00063223(99)00041-4

Rauch, S.A.M., Favorite, T., Giardino, N., Porcari, C., Defever, E., Liberzon, I., 2010. Relationship between anxiety, depression, and health satisfaction among veterans with PTSD. J. Affect. Disord. 121, 165-168. https://doi.org/10.1016/j.jad.2009.05.026

Salvadore, G., Nugent, A.C., Lemaitre, H., Luckenbaugh, D.A., Tinsley, R., Cannon, D.M., Neumeister, A., Zarate, C.A., Drevets, W.C., 2011. Prefrontal cortical abnormalities in currently depressed versus currently remitted patients with major depressive disorder. Neuroimage 54, 2643-2651. https://doi.org/10.1016/j.neuroimage.2010.11.011

Schiller, D., Monfils, M.H., Raio, C.M., Johnson, D.C., Ledoux, J.E., Phelps, E.A., 2010. Preventing the return of fear in humans using reconsolidation update mechanisms. Nature 463, 49-53. https://doi.org/10.1038/nature08637

Schlichting, M.L., Preston, A.R., 2016. Hippocampal-medial prefrontal circuit supports memory updating during learning and post-encoding rest. Neurobio. Learn. Mem. 134, 91-106.

Sheline, Y.I., Mittler, B.L., Mintun, M.A., 2002. The hippocampus and depression. Eur. Psychiatry 17, 300-305. https://doi.org/10.1016/S0924-9338(02)00655-7

Sheline, Y.I., Wang, P.W., Gado, M.H., Csernansky, J.G., Vannier, M.W., 1996. Hippocampal atrophy in recurrent major depression. Proc. Natl. Acad. Sci. 93, 3908-3913. https://doi.org/10.1073/pnas.93.9.3908

Simon, N.M., Otto, M.W., Wisniewski, S.R., Fossey, M., Sagduyu, K., Frank, E., Sachs, G.S., Nierenberg, A.A., Thase, M.E., Pollack, M.H., 2004. Anxiety disorder comorbidity in bipolar disorder patients: data from the first 500 participants in the Systematic Treatment Enhancement 
Program for Bipolar Disorder (STEP-BD). American J. Psychiatry 161, 2222-2229.

Spielberger, C.D., Gorsuch, R.C., Lushene, R.E., Vagg, P.R., Jacobs, G.A., 1983. Manual for the StateTrait Anxiety Inventory. Palo Alto: Consulting Psychologists Press.

Sterling, M. 2011. General Health Questionnaire-28 (GHQ-28). J Physiotherapy 57, 259.

Stickgold, R., Walker, M.P., 2007. Sleep-dependent memory consolidation and reconsolidation. Sleep Med, 8, 331-343.

Strakowski, S.M., Adler, C.M., Holland, S.K., Mills, N., DelBello, M.P., 2004. A preliminary fMRI study of sustained attention in euthymic, unmedicated bipolar disorder. Neuropsychopharmacology 29, 1734-1740. https://doi.org/10.1038/sj.npp.1300492

Sweeney, J.A., Kmiec, J.A., Kupfer, D.J., 2000. Neuropsychologic impairments in bipolar and unipolar mood disorders on the CANTAB neurocognitive battery. Biol. Psychiatry 48, 674-684. https://doi.org/10.1016/S0006-3223(00)00910-0

Treadway, M.T., Waskom, M.L., Dillon, D.G., Holmes, A.J., Park, M.T.M., Chakravarty, M.M., Dutra, S.J., Polli, F.E., Iosifescu, D. V., Fava, M., Gabrieli, J.D.E., Pizzagalli, D.A., 2015. Illness progression, recent stress, and morphometry of hippocampal subfields and medial prefrontal cortex in major depression. Biol. Psychiatry 77, 285-294. https://doi.org/10.1016/j.biopsych.2014.06.018

Tulving, E. 1964. Intratrial and intertrial retention: Notes towards a theory of free recall verbal learning. Psychol Review, 71, 219-236.

Turner, M.S., Simons, J.S., Gilbert, S.J., Frith, C.D., Burgess, P.W., 2008. Distinct roles for lateral and medial rostral prefrontal cortex in source monitoring of perceived and imagined events. Neuropsychologia 46, 1442-1453. https://doi.org/10.1016/j.neuropsychologia.2007.12.029

Van Gorp, W.G., Altshuler, L., Theberge, D.C., Mintz, J., 1999. Declarative and procedural memory in bipolar disorder. Biol. Psychiatry 46, 525-531. https://doi.org/10.1016/S0006-3223(98)00336-9

Vrabie, M., Marinescu, V., Talaşman, A., Tautu, O., Drima, E., Micluţia, I., 2015. Cognitive impairment in manic bipolar patients: Important, understated, significant aspects. Ann. Gen. Psychiatry 14, 110. . https://doi.org/10.1186/s12991-015-0080-0

Young, R.C., Biggs, J.T., Ziegler, V.E., Meyer, D.A., 1978. A rating scale for mania: reliability, validity and sensitivity. British J. Psychiatry, 133, 429-435. 